\title{
XXVI. On the curvature of spirit-levels
}

\section{J. Nixon Esq.}

To cite this article: J. Nixon Esq. (1829) XXVI. On the curvature of spirit-levels, Philosophical Magazine Series 2, 5:27, 174-178, DOI: 10.1080/14786442908674956

To link to this article: http://dx.doi.org/10.1080/14786442908674956

曲 Published online: 14 Jul 2009.

Submit your article to this journal $\widetilde{ }$

Џ Article views: 2

Q View related articles $₫$ 
i. Some small drops of fused ore, which very much resembled the imperfectly reduced ore of $a$ in the first experiment, occupied the bottom of the tube immediately at the end of the lime; but there was not a particle of pure lead formed in any part of the tube.

k. Four hundred grains of the gray-coloured lumps described in paragraph $f$, were assnyed with borax and tartar ; and a button of lead weighing 188 grains was obtained. From this tead a small globule of silver weighing $\frac{53}{10}{ }_{0} \mathrm{dth}$ grains was extracted by cupellation, which is after the rate of $13 \mathrm{oz}$. 3 dwts. 10 grs. per 21 cwit. avoidupois of lead, and is not more than night be expected from the sample of galena sabmitted to experiment.

From these experiments it appears, 1st, that the vapour of wate is decomposed by transmission over heated galena, its hydrogen uniting with a portion of the sulphur to form sulphuretted hydrogen gas, and its oxygen combining with the equivalent quantity of galena to form sulpkate of lead, to which the milkiness of the water in the two experiments is to be attributed. The galena, which gives up a portion of its sulphur to form sulphuretted hydrogen gas, is probably reduced to the state of sub-sulphuret of lead. 2ndly, Quick-lime is used in the lorge way to reduce the slags or scorize from lead ore into a pasty state, so that they can be more easily removed from the hearth or furnace; but it appears to have a very inconsiderable effect in promoting the reduction of galena; and hence the quantity used should be no more than may be sufficient to effect the purpose for which it is applied. 3rlly, The deposition of galena from its vapour in contact with steam in a highly crystalline form is an interesting circumstance. The crystals exactly resembled in appearance many specinens from the numerous lead-ore veins traversing the mountain limestone of this district, and might warrant at least the conjectrre, that galena in these veins has been in some instances supplied by sublimation from below. I am, Gentlemen, yours, \&c.

Lowleyer.Alston, Jan. 13, 1829.

H. L. Paxtinson.

XXVI. On the Curvature of Spirit-Levels. By J. Nixon, Esq.

To the Editors of the Philosophical Magazine and Annals. Gentlemen,

QOME years ago I received from Mr. Dollond four ground spirit-levels (unmounted), of which two served to replace the much less sensible original levels of the horizon-sector alluded to in Phil. Mag. and Annals, vol. iii. page 190. The tubes 
tubes were abont six inches long, nearly half an inch in diameter, slightly conical, and their bubbles were estimated to move the one-fortieth part of an inch for a variation of inclination equal to one second.

Conceiving that the reversing points of the levels of the horizon-sector might be more immediately and correctly ascertained from scales of equal parts attached to the tubes, than by determining from measurements on the graduated arcs the situation of these points relative to the fixed marks drawn on the surface of the tubes, it became necessary to verify the estimated curvature of the levels. In the accomplishment of this object, the sector afforded singular facilities; but as the manipulation of the instrument, may not be generally understood, I prefer pointing out the method by which the level of the telescope of a good theodolite may be mounted with a scale, and the angular value of its divisions obtained.

For the scale; cut a piece of moderately stiff paper into the form of a parallelogram of the proper length, and about a quarter of an inch wide, and press. it evenly upon the glass tube, previously spread over with liquid glue, with either of its longitudinal edges laid exactly upon the line of curvature or straight line passing (in the direction of the axis of the tube) through the middle points of the twa bubble-marks. When the scale is quite dry, divide this edge into minute equal parts, and number them from zero, placed at that end of the scale the nearest to the eye-piece of the telescope, progressively to the other extremity.

To find the angular value of the divisions, set up. and fix the theodolite in a situation inaccessible to the direct rays of the sun, and adjust the instrument for observation with the divided edge of the scale perpendicular to the optical axis: of the telescope, and with the zero of the vertical axch in a line with that of its vernier. Having clamped the horizontal circles with the telescope exactly over two (opposite) screws of the parallel plates, make use of these screws to force the bubble of its level to the zero extremity of the scale..When at rest, register in one column, which designate, " telescope depressed," the distance of each end of the bublule from the zero of the scale. The bubble being moved, in the next.places by the aid of the tangent-screw, or rack-work of the vertical arch to the other extremity of the scale, note the distance from zero of each of its. ends, and enter them in a separate column to be termed, "telescope elevated." Half the difference of the sum of each column is evidently the space traversed by the bubble, of which the corresponding angle (of elevation) will be given on the vertical arch. To insure to the measurements the re- 
quisite degree of accuracy, it will, however, be necessary, as an error of one minute might be committed in the graduation of the arc, or in the reading off, to continue the operation of first depressing the telescope by the same screws of the parallel plates, and of subsequently elevating it by the tangent-screw of the vertical arch, noting in the proper column after every depression or elevation of the telescope the distance of the ends of the bubble from the zero of the scale, until a sufficient mulkiple of the mean angle shall be obtained. Lastly, find the sum of each column, and divide the angle read off the vertical arch by half their difference, which will give the value in seconds of one division of the scale. The original scale may now be taken off, and the one substituted, divided into equal parts of one second each. A black-lead pencil being used in marking and numbering the divisions, the whole may be varnished over to prevent obliteration, \&c.

The reversing point of a similar level will be equal to onefourth of the sum of the divisions from zero of the extremities of the bubble noted before and after reversing the telescope within its Ys. Temporary reversing marks may be conveniently made on the tube with a camel-hair pencil dipped in white water-colour; each mark being equidistant from the division, answering to the reversing point by half the length of the bubble. In addition to the facility and accuracy with which minute vertical angles may be measured on a similar scale, it would be found particularly serviceable in a novel method of levelling, of which I shall beg leave at some future opportunity to transmit a notice.

The two levels of the horizon-sector are mounted in brass cases, in which, as the telescope requires to be inverted at every other observation, they are necessarily fitted as closely as practicable. Each division of the scale of forty to the inch, was found from repeated trials with the sector, to be $1^{1 / .906}$ in the right-hand level, and $2^{\prime \prime} \cdot 124$ in the other; or double the estimated value. As the (glass) tubes are slightly flexible, I suspected that their curvature might have been augmented in the mounting, and made the following experiments with the shortest of the two spare levels, with a view to gain information on the subject.

Experiment I.-Two Ys, cut out of a mahogany board $0 \cdot 1$ inch thick, were glued to the upper surface of an inflexible bar of oak laid securely on the cylinder of the sector. The short level furnished with a scale was then placed quite loose within the Ys, each end overhanging its $\mathbf{Y}$ by one-third of the length of the tube. The space traversed by the bubble of the short level being compared with that passed over by the bubble of 
one of the levels of the sector, the variation of inclination being the same for both levels, it appeared that one division of the scale of the former, also of forty to the inch, was equal to $1^{1 / 4} 480^{*}$. (In this and the following experiments, the axis of the short level was invariably made parallel to that of the sector level, the line on which the divisions are drawn being perpendicular in the two levels to their respective axes. As neither of the levels might be uniformly curved throughout, they were rendered strictly parallel in horizontal inclination; and care was taken never to drive the bubbles completely to the extremities of the tubes. The values quoted are the mean of three or four satisfactory measurements of about $100^{\prime \prime}$ each.

No. Il.-The Ys being thinly coated with glue, the level was placed gently within them in the preceding position, and suffered to dry without pressure. The divisions were then found to be $1^{1 / \cdot 683}$ each.

No. III. - The level was placed on the even surface of one of the brass indices of the sector previously spread over with glue, and left to dry. The divisions were now $11 \cdot 679$ each.

No. IV.-The level being glued to the surface of a mahogany bar, eight inches long by one inch square, fixed to the cylinder of the sector, the divisions, after a lapse of a couple of days, were found to be $1^{\prime \prime} \cdot 854$ each. On repeating the measurement on the following day, the value appeared to be $1^{11}: 853$.

No. V.-The level was mounted in a brass case with a degree of tightness barely sufficient to preserve it unvaried in position.-Value of one division $=1^{\prime \prime} \cdot 684$.

No. VI.-The level being loose within the case, the packing (with cotton wool) was confined to the ends of the tube.-Value of one division $=1^{11 \cdot 915}$. It must be supposed that the mere pressure of the packing had distorted the tube; otherwise, why did the curvature differ from its value in the first experiment?

No. VII.-The level was placed, unattached, within the mahogany Ys, overhanging two inches at the smaller end of the tube, and scarcely half an inch at the opposite end. - Value of one division $=1^{\prime \prime} \cdot 615$.

No. VIII.-The Ys being set up more distant from each other, the level, placed within them unattached, extended at each end no more than a quarter of an inch beyond the Ys. - Value of one division $=1^{H \cdot 703}$. The mere weight of the level, it would appear, had not diminished the degree of curvature.

* The mean of four preceding measurements, rejected on account of a slight difference in the degree of inclination of the two levels, gave $1^{\prime \prime} \cdot 479$ for the value of one division.

N. S. Vol. 5. No. 27. March 1829.

$2 \mathrm{~A}$

Al- 


\section{Rev. W. V. Vernon's Analysis of an aluminous Mineral}

Although the differing results of the experiments afford little satisfactory explanation of the causes of the variations in the curvature of the levels, and one or two might have been differently anticipated, they amply serve to prove that the mounting tends to render them less sensible, and point out the necessity of verifying the accuracy of the scales furnished by the artist.

Leeds, Dec. $20,1828$.

J. Nixon.

XXVII. Analysis of an aluminous Mineral in the Collection of the Yorkshire Philosophical Society. By the Rev. William V. Vennon, F.R.S. F.G.S. Pres. of the Yorkshire Philosophical Society*.

THE calcareous rock on the coast at Scarborough, which

Mr. Smith considers as corresponding with the great oolite of Bath, is covered by beds of sandstone much marked with oxide of iron. Whilst I was examining these beds in 1826, my attention was attracted by a mineral + , with which they are in many parts veined, of a white colour, but not bearing, to my eye, the appearance of calcareous spar. Finding that this substance had the property of adhering strongly to the tongue, I conceived it to be probably aluminous, and presented a specimen under that character to the Yorkshire Philosophical Society, after having ascertained that sulphuric acid and potash converted the greater part into alum. I have lately examined it more accurately, and find it to differ from any of the aluminous minerals which have been yet described.

The mineral when pure is perfectly white, without lustre, with a conchoidal fracture, easily scratched by the knife, and polished by the nail; it is highly adhesive to moist surfaces; when breathed upon, it has a strong earthy smell; when put into water, it does not become translucent nor fall to pieces, but gains considerably in weight. The absolute specific gra-

* Communicated by the Author.

+ In the account of these beds prepared by Mr. J. Phillips for his forthcoming publication on the Geology of Yorkshire, the veins here mentioned are thus described: "The calcareous and irony strata (great oolite, Smith) have their long straight intersecting fissures often lined with double laminze or septa of oxide of iron, between which sometimes occurs a white cumpact, soft, smooth substance, which the Rev. W. Vernon has ascertained to be a new aluminous mineral; exactly similar septa, and occasionally the same aluminous substance occur in the superincumbent variable beds of sandstone; and in addition, this bed presents a number of ochraceous belts or zones parallel to the margins of the blocks, and beautifully variegating the blue or white colour of the stone." 